\title{
Old problems and new challenges in understanding past ocean circulation and carbon-cycle changes
}

\author{
Julia Gottschalk' , X. Zhang ${ }^{2}$ and A. Burke ${ }^{3}$
}

This Past Global Changes Magazine issue celebrates achievements in our understanding of the mechanisms governing changes in ocean circulation and the global carbon cycle in the past, and the complex interplay between them. This issue also emphasizes the current challenges and open questions in the field, to motivate research into improving our understanding of the fundamental links between ocean circulation, carbon cycling, and climate in the past, as well as in assessing the implications for the future.

This year, we mourn the loss of Wallace (Wally) Smith Broecker (1931-2019), professor of Geology at Columbia University. Wally was truly a "conveyor belt" of ideas and remarkable accomplishments in the fields of chemical oceanography and paleoclimatology, and his intellectual legacy has nurtured and will continue to nurture generations to come. His memoir (Broecker 2012) is a highly recommended read, as it also provides an overview of how (paleo-)ocean sciences evolved during his career.

Since the last assessment report of the Intergovernmental Panel on Climate Change (IPCC) in 2013 (Stocker et al. 2013), atmospheric $\mathrm{CO}_{2}$ levels have risen as a result of human activities by a magnitude similar to past millennial $\mathrm{CO}_{2}$ changes (e.g. Bereiter et al. 2015), though at a much faster rate. In this year's Special Report on the Ocean and Cryosphere in a Changing Climate (ipcc.ch/ srocc; Pörtner et al. 2019), IPCC has, for the first time, highlighted a recognizable weakening of the Atlantic Meridional Overturning Circulation relative to 1850-1900. These observations emphasize the ongoing dramatic changes in the Earth's climate system today. Studying the fingerprints and records of past climate changes in diverse geological archives provides our best opportunity to document and assess the fundamentals of Earth's climate system under a variety of (extreme) climate boundary conditions.
The advent of stable isotope analyses of calcareous marine fossils (e.g. foraminifera) and ice-core drilling in the 1950s has provided crucial insights into past ocean and climate variability. Nearly 70 years later, the field of paleoceanography is an amalgamation of different techniques applied to study climate variability on various timescales based on many archives. However, overarching questions that motivated Earth scientists decades ago remain of great interest to the paleocommunity: What leads to changes in ocean circulation and how has it varied in the past? What drives the variations in greenhouse gas concentrations in the atmosphere?

To address these questions, the Ocean Circulation and Carbon Cycling working group (OC3, pastglobalchanges.org/oc3), which launched in 2014, has worked towards a global synthesis of stable isotope data from foraminifera and their comparison with numerical model simulations (e.g. Muglia et al. 2018). This effort is geared towards assessing deglacial circulation dynamics of different water masses globally and their role in changing ocean carbon storage over time. While a core-top (i.e. Late Holocene) data compilation has been completed and successfully compared against pre-industrial ocean observations (e.g. Schmittner et al. 2017), comprehensive regional and global data products for the last glacial-interglacial transition will be released in the near future.

In addition to using traditional stable-isotope proxies, paleoceanographers, geo chemists, and Earth-system modelers distill information from paleodata constraints of past ocean and carbon-cycle dynamics that are derived from a number of proxies, many of which are discussed in this issue. Furthermore, in order to understand climate thresholds and sensitivities, it is important to study a range of climate boundary conditions in the past. Key intervals discussed in this magazine include the last deglaciation, the mid-Pleistocene transition, the Pliocene, and the Paleocene-Eocene Thermal Maximum. However, accurately estimating variations of global geochemical ocean inventories on a variety of timescales, and quantitatively determining the implications for ocean circulation, climate, and the global carbon cycle, remain major challenges. As some authors highlight, community-wide efforts of synthesizing regional data into a global framework and combining different proxy approaches will be important for addressing these challenges, as well as developments of numerical models and modeldata assimilation efforts. This issue therefore aims to motivate future scientific research on these crucial aspects in our quest to improve our understanding of mechanisms behind past ocean circulation and global carboncycle dynamics.

\section{AFFILIATIONS}

'Lamont-Doherty Earth Observatory, Columbia University, Palisades, NY, USA

Lanzhou University, China, and Alfred Wegener Institute, Helmholtz Center for Polar and Marine Research, Bremerhaven, Germany

${ }^{3}$ School of Earth and Environmental Sciences, University of St. Andrews, UK

\section{CONTACT}

Julia Gottschalk: jgottsch@|deo.columbia.edu

\section{REFERENCES}

Bereiter B et al. (2015) Geophys Res Lett 42: 542-549

Broecker WS (1987) Nat Hist 97: 74-82

Broecker WS (2012) Geochemical Perspect 1: 221-343

Muglia J et al. (2018) Earth Planet Sc Lett 496: 47-56

Pörtner $\mathrm{H}-\mathrm{O}$ et al. (in press) IPCC Special Report on the Ocean and Cryosphere in a Changing Climate

RahmstorfS (2002) Nature 419: 207-214

Schmittner A et al. (2017) Paleoceanography 32: 512-530

Stocker TF et al. (2013) Climate Change 2013: The

Physical Science Basis. Cambridge University

Press, $1535 \mathrm{pp}$

Talley LD (2013) Oceanography 26: 80-97

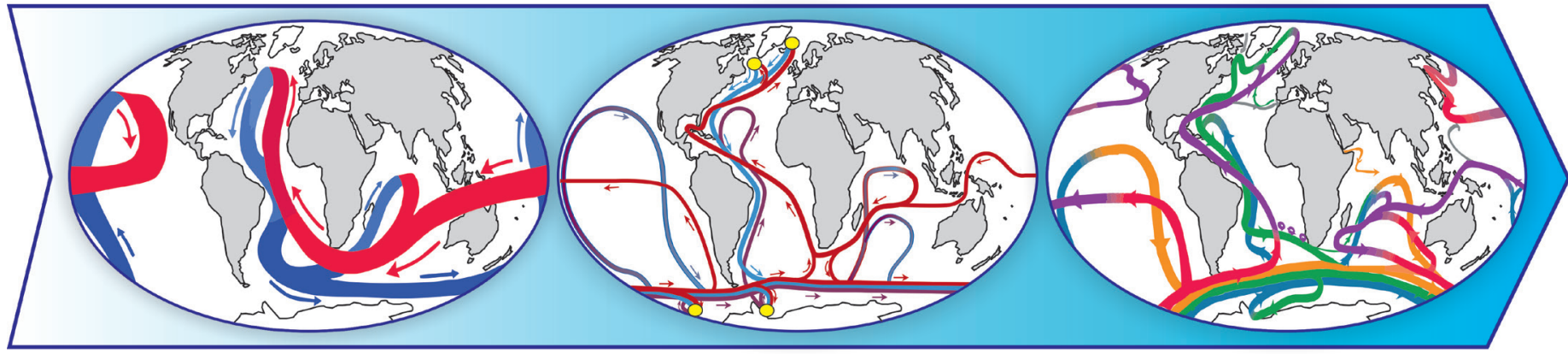

Figure 1: Our understanding of processes and feedbacks between different components of the Earth system has remarkably expanded over the last decades, here illustrated by conceptual visualizations of global ocean circulation over time: from the "Great Ocean Conveyor Belt" (left; Broecker 1987), to more complex ocean circulation dynamics (middle) with different deep water formation sites (yellow dots; Rahmstorf 2002) and (right) to an ocean with different water masses that interact and interfere with each other in a complex manner (Talley 2013). Different colors depict different types of water masses (see aforementioned references). 